\title{
Ludwig's Angina, Difficult Airways Management: Case Report
}

\author{
GLD’Agostino*1 $^{*}$ A Nicchi $^{1}$, E Fiorello ${ }^{2}$ and A Gattuso ${ }^{3}$ \\ ${ }^{1}$ UOC Anesthesia and Reanimation PO Partinico (Asp 6 Palermo), Italy \\ ${ }^{2}$ UOC Emergency Medicine and Acceptance PO Partinico (Asp 6 Palermo) Anesthesia and Reanimation PO Partinico (Asp 6 Palermo), Italy \\ ${ }^{3}$ UOC Radio prostagostatic imaging PO Partinico (Asp 6 Palermo), Italy \\ *Corresponding author: Giovanni Luca D Agostino, UOC Anesthesia and Reanimation PO Partinico (Asp 6 Palermo), Italy
}

\begin{tabular}{|c|c|}
\hline ARTICLE INFO & ABSTRACT \\
\hline Received: 㗀 February 04, 2019 & Citation: GLD’Agostino, A Nicchi, E Fiorello, A Gattuso. Ludwig's Angina, Difficult Airways \\
\hline Published: 幽 February 12, 2019 & Management: Case Report. Biomed J Sci \& Tech Res 14(3)-2019. BJSTR. MS.ID.002547. \\
\hline
\end{tabular}

\section{Introduction}

Ludwig's Angina is a rare but life-threatening condition. Managing high airways to provide adequate ventilation and oxygenation, tracheostomy, broad spectrum antibiotics, and surgery are the principle treatments.

\section{Methods and Case}

A 24 years old male patient came in emergency room, with severe neck pain, respiratory failure and, above all, severe trismus, enlarged tongue, inability in swallowing, e swelled neck. TC showed widespread oedemas with free fluids and severe crush of larynx and tracheal reduced caliber and left dislocation, a necrotizing fascitis, and a severe pneumonia and mediastinitis. At IC unit, where difficult airways management facilities were prepared, we solved trisma with propofol, and performed 3 laryngoscopy attempts without success, due to a massive tongue and mucoses oedema and necrotic fluids in hypofarynx, removed by aspiration. Even not glydescope videolaryngoscopy allowed direct or indirect airways vision [1].

\section{Results and Discussion}

we succeed with laryngeal mask (impossible to attempt tracheostomy for the imponent neck oedema), passed a $n^{\circ} 6$ tube through it and moved to 'Vincenzo Cervello' Hospital for surgical tracheostomy. Afterwards, once stabilized, the patient was conducted to Ismett hospital for ARDS therapy with ECMO, where he stayed for about 6 months before definitive, complete, clinical recovery [2] (Figures 1-3).

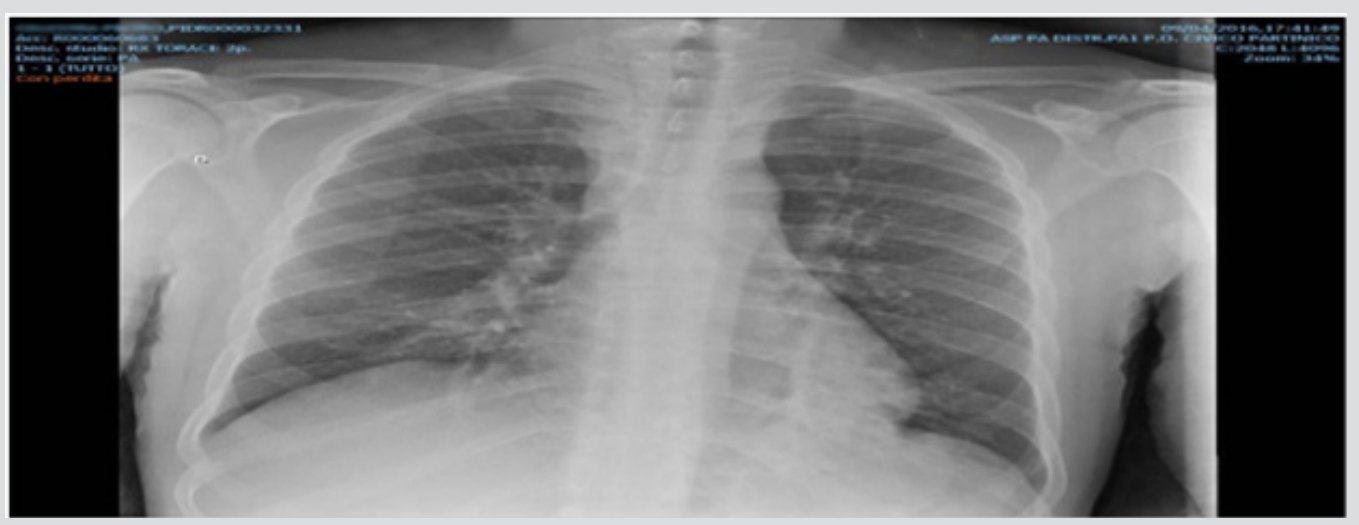

Figure 1. 


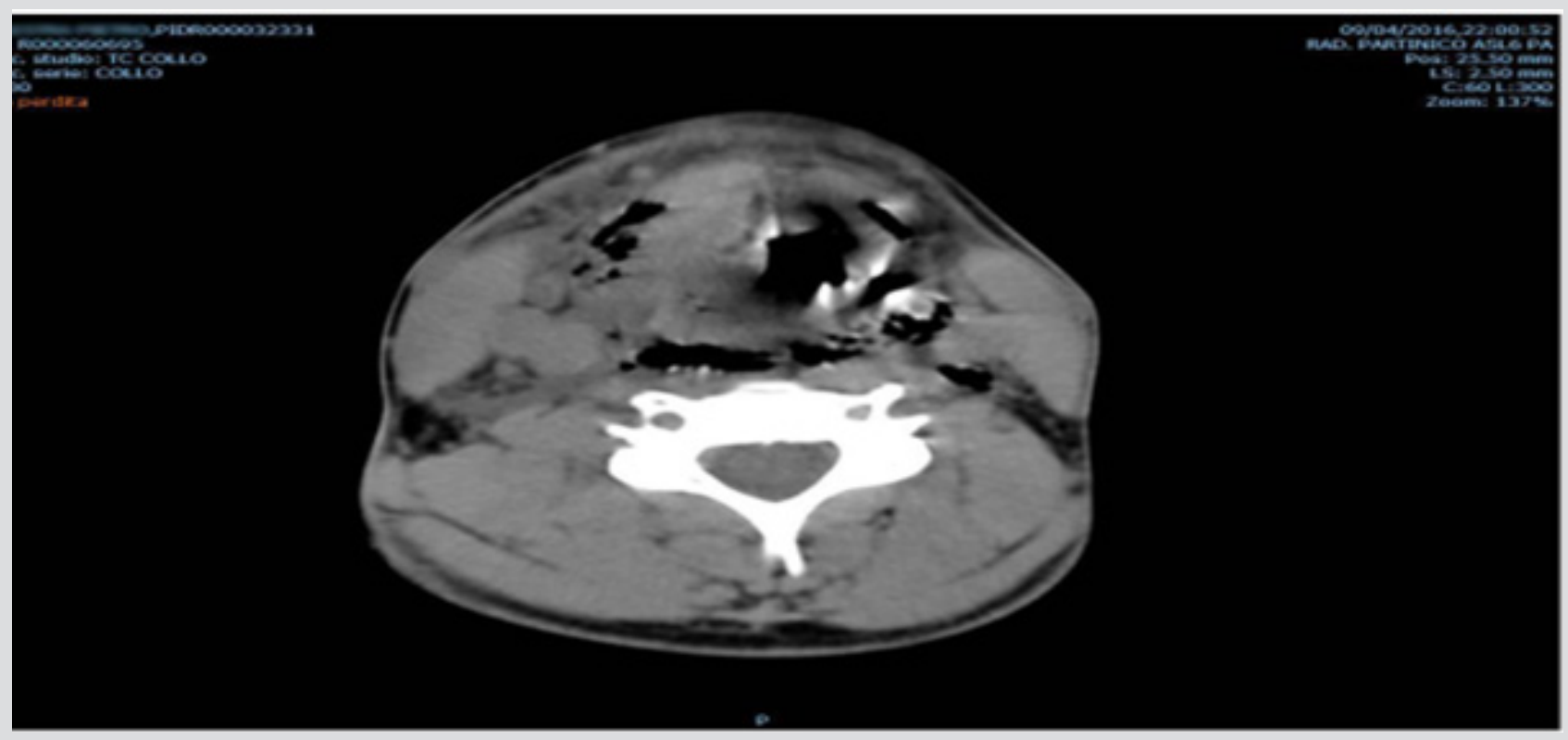

Figure 2.

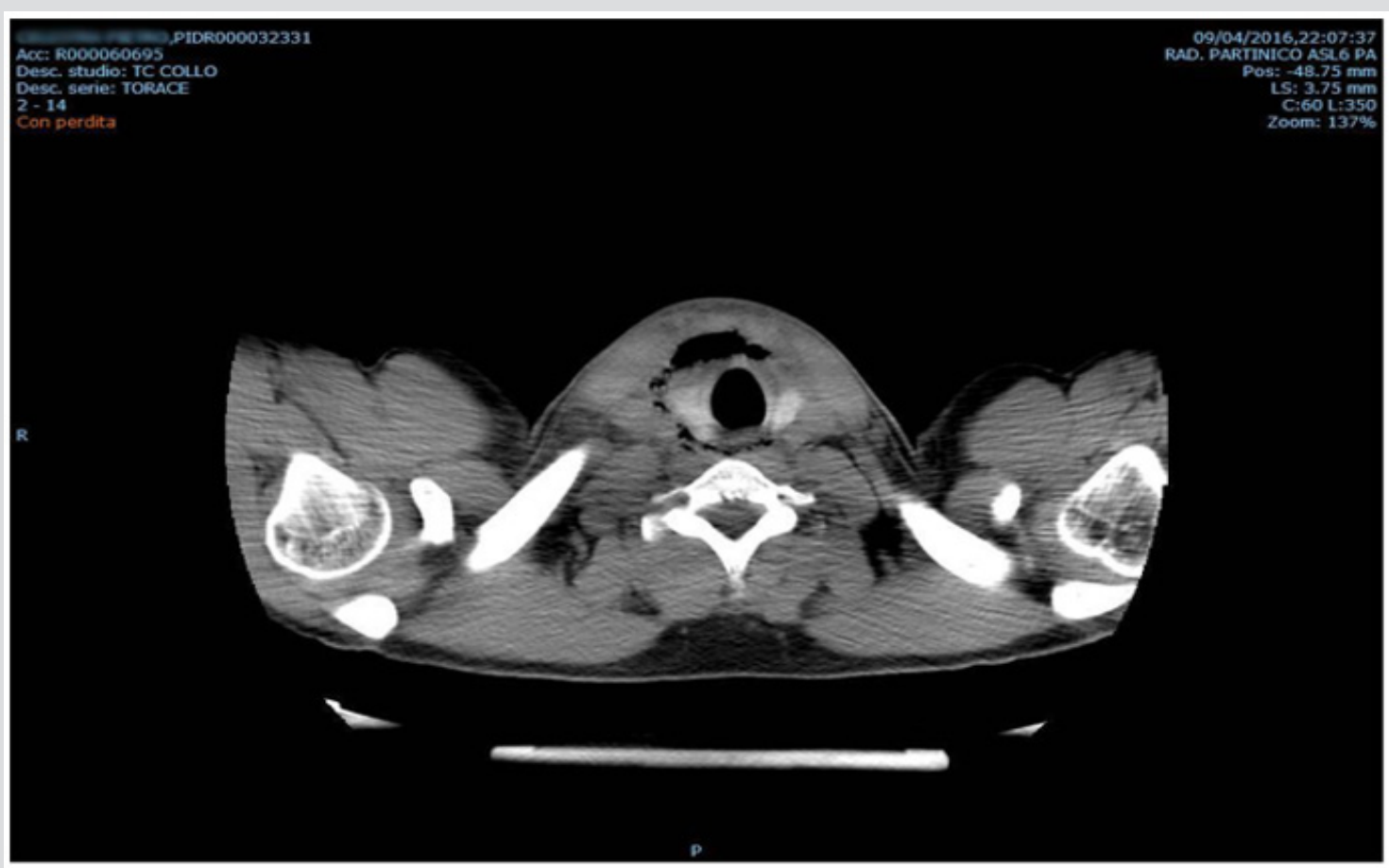

Figure 3.

\section{Conclusion}

Patients with deep neck infections are a strong challenge for an anaesthesiology to perform airways management due to the rapid, severe obstruction. The choice of the best technique depends from the patient's conditions, the presence of suitable facilities, and skills and experiences of the operator.

\section{References}

1. Durand M, Joseph M (2001) Infections of the upper respiratory tract. In Harrison's Principles of International Medicine $\left(16^{\text {th }}\right.$ edn.). In: Braunwald E, Fauci AS, Kasper DL, JL McGraw-Hill (Eds.), New York, USA, 1: 191.

2. Mohd Razif Mohd Yunus, Fadzlina Abdul Karim, SHA Primuharsa Putra, Roslan Abdul Rahman, Heng Swee Heong, et al. (2006) Ludwig's Angina; A Retrospective study of seven cases. Asian J Oral Maxillofac Surg 18: 263-267. 
ISSN: 2574-1241

DOI: 10.26717.BJSTR.2019.14.002547

Giovanni Luca D Agostino. Biomed J Sci \& Tech Res

(C) (i) This work is licensed under Creative

Submission Link: https://biomedres.us/submit-manuscript.php

$\begin{array}{ll}\text { BIOMEDICAL } & \begin{array}{l}\text { Assets of Publishing with us } \\ \text { RESEARCHES }\end{array} \\ \text { - Global archiving of articles } \\ \text { - Immediate, unrestricted online access } \\ \end{array}$

